Article

\title{
The Influence of Powder Milling on Properties of SPS Compacted FeAl
}

\author{
Alena Michalcová ${ }^{1, *}$, Murat Özkan ${ }^{1}$, Pavol Mikula ${ }^{2}$, Ivo Marek ${ }^{1}$, Anna Knaislová ${ }^{1}$, \\ Jaromír Kopeček ${ }^{3}$ iD and Dalibor Vojtěch ${ }^{1}$ \\ 1 Departments of Metals and Corrosion Engineering, University of Chemistry and Technology, \\ 16628 Prague 6, Czech Republic; muratozkan473@hotmail.com (M.Ö.); mareki@vscht.cz (I.M.); \\ knaisloa@vscht.cz (A.K.); vojtechd@vscht.cz (D.V.) \\ 2 Nuclear Physics Institute ASCR, v.v.i., 25068 Řež, Czech Republic; mikula@ujf.cas.cz \\ 3 FZU-Institute of Physics of the CAS, Na Slovance 1999/2, 18221 Prague 8, Czech Republic; kopecek@fzu.cz \\ * Correspondence: michalca@vscht.cz; Tel.: +420-22044-2042
}

Academic Editors: Pavel Novak, Giuseppe Cirillo and Venkatesh Vijayaraghavan Received: 31 March 2020; Accepted: 7 May 2020; Published: 11 May 2020

check for updates

\begin{abstract}
The Fe-28 at.\% Al alloy was studied in this article. The aim was to describe the influence of gas atomized powder pre-milling before SPS (Spark Plasma Sintering) sintering on the structure and properties of the bulk materials. The initial powder was milled for $0.5,1$, and $8 \mathrm{~h}$. It was proven that $1 \mathrm{~h}$ milling leads to the change in size and morphology of the particles, B2 $\rightarrow \mathrm{A} 2$ phase transformation, and to the contamination with the material from a milling vessel. Powder materials were compacted by the SPS process at 900,1000 , and $1100{ }^{\circ} \mathrm{C}$. The differences between the bulk materials were tested by LM, SEM, and TEM microscopy, XRD, and neutron diffraction methods. It was proven that, although the structures of initial powder (B2) and milled powder (A2) were different, both provide after-sintering material with the same structure $\left(\mathrm{DO}_{3}\right)$ with similar structural parameters. Higher hardness and improved ductility of the material sintered from the milled powder are likely caused by the change in chemical composition during the milling process.
\end{abstract}

Keywords: FeAl; ball milling; SPS compaction; neutron diffraction

\section{Introduction}

Fe-Al alloys are well-known for their many attractive properties such as low cost, low density, and good corrosion resistance [1-5]. The Fe-Al alloys with about 20-50 at.\% Al are called iron aluminides. The Fe-Al alloys can be used for structural application at high temperatures because they have high temperature strength. This shows that it might replace stainless steels in some applications [6,7]. They are also potential materials for special uses such as fuel injector nozzles [8-10], automobile exhaust systems [11], and fuel filter elements in coal gasification systems [10].

The major issues in the mechanical properties of the Fe-Al alloys is their poor room temperature ductility. The solutions might be in the grain size refinement. It was proven that the Fe-Al alloy with a grain size less than $10 \mu \mathrm{m}$ should be sufficiently ductile for industrial processing [12]. Material with this grain size is not obtainable by the conventional methods like casting and must be produced by advanced technologies consisting of two steps. In the first step, powder is prepared. High energy ball milling and atomization are among the most common methods for obtaining fine powder with fine grains $[7,13]$. The second step in obtaining bulk fine-grained materials is powder compaction. Several consolidation methods are available such as rapid sintering $[14,15]$, spraying processes like high velocity oxy fuel (HVOF) [15], cold spraying [16], hot compression [17], hot isostatic pressing [18], detonation gun [19], additive manufacturing [20], and spark plasma sintering (SPS) [13-15,21-28]. 
Preparation of the $\mathrm{Fe}_{3} \mathrm{Al}$-based materials by mechanical alloying form pure $\mathrm{Fe}$ and $\mathrm{Al}$, which is followed by the SPS (spark plasma sintering) process already described [29-31]. The long-term milling process carried out in a stainless-steel vessel led to contamination of the milled material by carbon and consequent formation of carbides [30,31]. Their presence causes extreme brittleness of the material. To cut down the amount of contamination, the gas atomized powder was used instead of the pure elements in this work. The milling time needed to decrease the grain size is shorter than the one necessary for iron aluminides formation.

It was shown [32] that the Fe-28 at.\% Al material prepared by melt atomization contained grains with an average size of $8 \mu \mathrm{m}$. Additive manufacturing of this powder led to production with a significantly larger grain size. According to the study on the Fe-43 at.\% $\mathrm{Al}$ [33], the temperature of $1000{ }^{\circ} \mathrm{C}$ should be sufficient to obtain a compact material. In this work, the influence of sintering temperature and influence of pre-milling on the microstructure and properties of the bulk Fe-28 at.\% Al materials (denoted as Fe28Al) were studied on the basis of X-ray diffraction, neutron diffraction, and microscopy.

\section{Results and Discussion}

Chemical composition of the initial Fe28Al was analyzed by X-Ray fluorescence spectroscopy (XRF) and the results are given in Table 1.

Table 1. Chemical composition of Fe28Al powder in the initial state and after milling for $0.5,1$, and $8 \mathrm{~h}$ measured by XRF.

\begin{tabular}{ccccccc}
\hline Element & Initial Powder & $\mathbf{0 . 5}$ h Milled & $\mathbf{1}$ h Milled & $\mathbf{8}$ h Milled & $\begin{array}{c}\text { Comp. } \\
\text { Initial }\end{array}$ & $\begin{array}{c}\text { Comp. } \\
\mathbf{8} \text { h Milled }\end{array}$ \\
\hline $\mathrm{Fe}$ & $83.34 \pm 0.10$ & $88.44 \pm 0.20$ & $86.90 \pm 0.20$ & $86.28 \pm 0.20$ & $86.10 \pm 0.50$ & $83.70 \pm 0.60$ \\
$\mathrm{Al}$ & $16.50 \pm 0.08$ & $10.34 \pm 0.09$ & $11.50 \pm 0.10$ & $4.58 \pm 0.06$ & $13.66 \pm 0.10$ & $8.23 \pm 0.10$ \\
$\mathrm{Cr}$ & $0.02 \pm 0.01$ & $0.61 \pm 0.02$ & $0.93 \pm 0.03$ & $6.18 \pm 0.03$ & $0.04 \pm 0.01$ & $5.47 \pm 0.10$ \\
$\mathrm{Mn}$ & $0.04 \pm 0.01$ & $0.08 \pm 0.01$ & $0.10 \pm 0.01$ & $0.73 \pm 0.02$ & $0.06 \pm 0.01$ & $0.34 \pm 0.03$ \\
$\mathrm{Si}$ & $0.10 \pm 0.01$ & $0.32 \pm 0.02$ & $0.52 \pm 0.02$ & $1.21 \pm 0.03$ & $0.14 \pm 0.01$ & $1.62 \pm 0.05$ \\
$\mathrm{Ni}$ & n.d. & $0.06 \pm 0.01$ & $0.04 \pm 0.01$ & $0.48 \pm 0.02$ & n.d. & $0.36 \pm 0.06$ \\
$\mathrm{Co}$ & n.d. & $0.16 \pm 0.01$ & n.d. & $0.54 \pm 0.02$ & n.d. & $0.28 \pm 0.03$ \\
\hline \multicolumn{7}{c}{ "n.d" - not detected. The results are given in wt. } \\
\end{tabular}

Table 1 shows the composition of powders after ball milling for different times. Contamination by material from a milling vessel (stainless steel) can be observed. The increase of content for powder milled for 0.5 and $1 \mathrm{~h}$ is up to $1 \mathrm{wt} . \%$ for all the impurity elements, but the change after $8 \mathrm{~h}$ of milling is significant. Comparing the contents of $\mathrm{Ni}$ and $\mathrm{Cr}$, it can be seen that the contamination is not uniform for elements forming the stainless-steel vessel $(18 \% \mathrm{Cr}, 10 \% \mathrm{Ni})$. To prove that the high $\mathrm{Cr}$ content was not caused by an experimental error, the composition of SPS sintered material was also analyzed (see Table 1). The Cr contamination originating from the milling vessel have not been described yet. On the other hand, contamination by $\mathrm{C}$ is known [30,31].

Figure 1 shows phase compositions of the initial and the milled powders. The initial powder has $\mathrm{B} 2$ phase composition (ordered $\mathrm{FeAl}$ ), proven by the presence of the characteristic peak at $30.7^{\circ}$. All the milled powders exhibit the A2 structure (disordered FeAl). The equilibrium composition of the $\mathrm{Fe} 28 \mathrm{Al}$ at room temperature is $\mathrm{Fe}_{3} \mathrm{Al}$ in the $\mathrm{D0}_{3}$ structure. The transformation temperatures for a similar alloy were estimated to be $543{ }^{\circ} \mathrm{C}$ for $\mathrm{D0}_{3} \leftrightarrow \mathrm{B} 2$ and $868{ }^{\circ} \mathrm{C}$ for $\mathrm{B} 2 \leftrightarrow \mathrm{A} 2$ [34,35]. The initial powder was processed by gas atomization and this technique is often used for rapid solidification. Because of this kinetic reason, the B2 structure was frozen to the room temperature. The ball-milling process involves high energy that is used for mechanical deformation but also partially for heating of the material. Due to this severe thermoplastic deformation, the Fe28Al transformed into the A2 phase. 


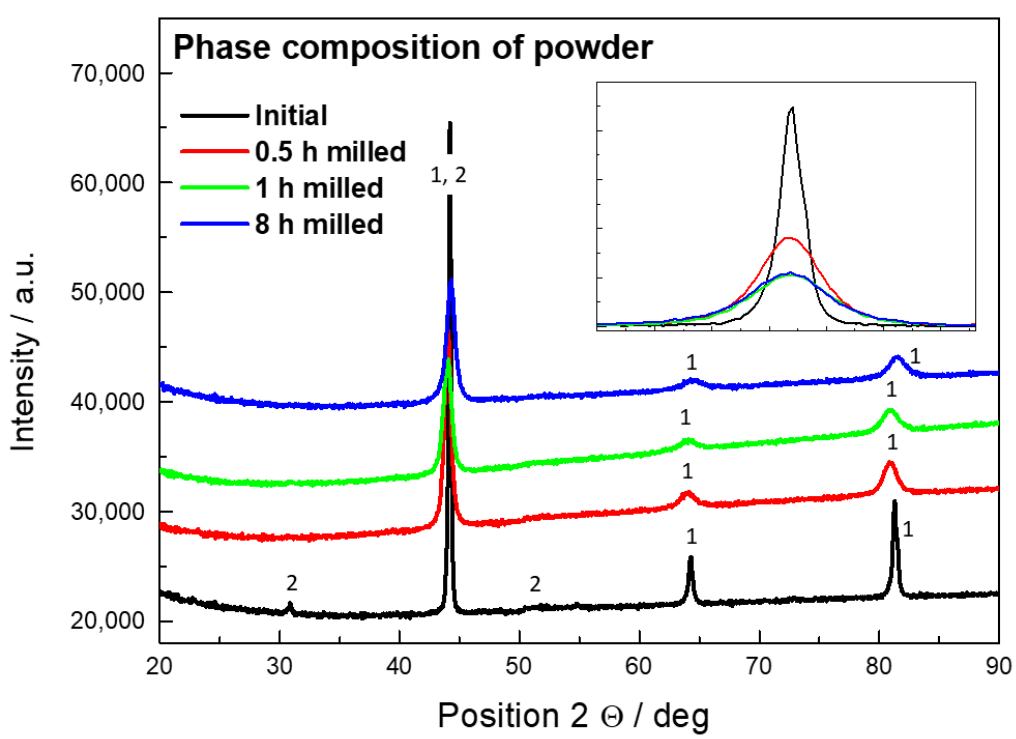

Figure 1. XRD pattern of Fe28Al powder in the initial state and after milling for $0.5,1$, and $8 \mathrm{~h}, 1-\mathrm{A} 2$ FeAl, 2-B2 FeAl.

The peaks from the 0.5 -h milled powder exhibit less broadening than those from the 1-h milled powder, as can be seen in a detail window in Figure 1. The crystallite (coherently diffracting domain) sizes estimated by Scherrer calculator are given in Table 2. The difference in crystallite size between the 1-h and the 8-h milled powder was not significant, while the difference in contamination is huge. For further work, the powder milled for $1 \mathrm{~h}$ was chosen.

Table 2. Crystallite size of Fe28Al powder in the initial state and after milling for $0.5,1$, and $8 \mathrm{~h}$ measured by the Scherrer calculator from XRD patterns, given in $\mathrm{nm}$.

\begin{tabular}{ccccc}
\hline Material & Initial Powder & $\mathbf{0 . 5}$ h Milled & $\mathbf{1 ~ h}$ Milled & $\mathbf{8}$ h Milled \\
\hline Crystallite size & $392 \pm 29$ & $160 \pm 5$ & $135 \pm 29$ & $124 \pm 28$ \\
\hline
\end{tabular}

The evolution of morphology of powder particles after $1 \mathrm{~h}$ milling is shown in Figures 2 and 3. The particles of the initial powder had a spherical shape, while the particles of the 1-h milled powder were irregular. The particle size estimated from metallographic samples was $18 \pm 10 \mu \mathrm{m}$ for the initial powder (in agreement with used granulometric fraction $\leq 45 \mu \mathrm{m}$ ) and $58 \pm 28 \mu \mathrm{m}$ for the 1 -h milled powder.
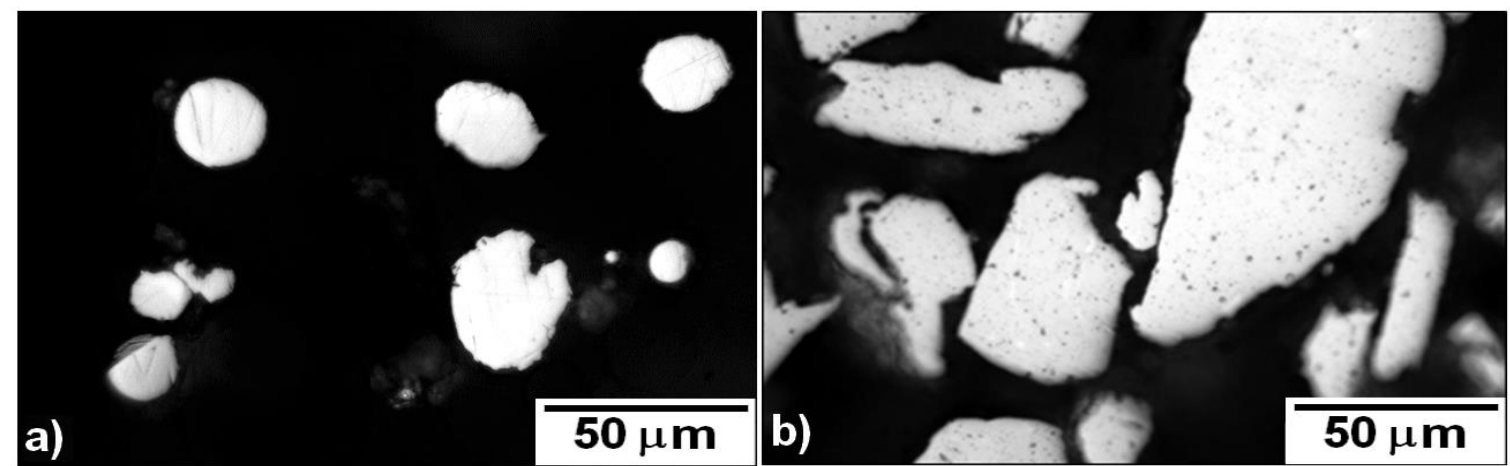

Figure 2. Optical micrographs of Fe28Al powder particles: (a) original and (b) 1-h milled.

Detailed observation by SEM confirmed changes in the morphology of powder particles. The initial powder is formed of spherical particles that are partially clustered as a consequence of the atomization 
process. The 1-h milled powder particles have irregular shape originating in welding and crushing of the initial spherical particles.

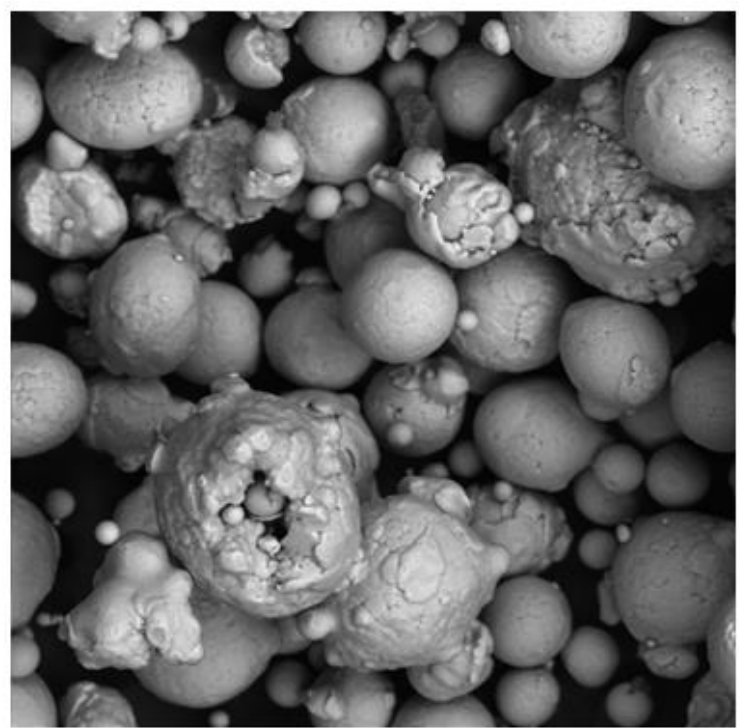

a)

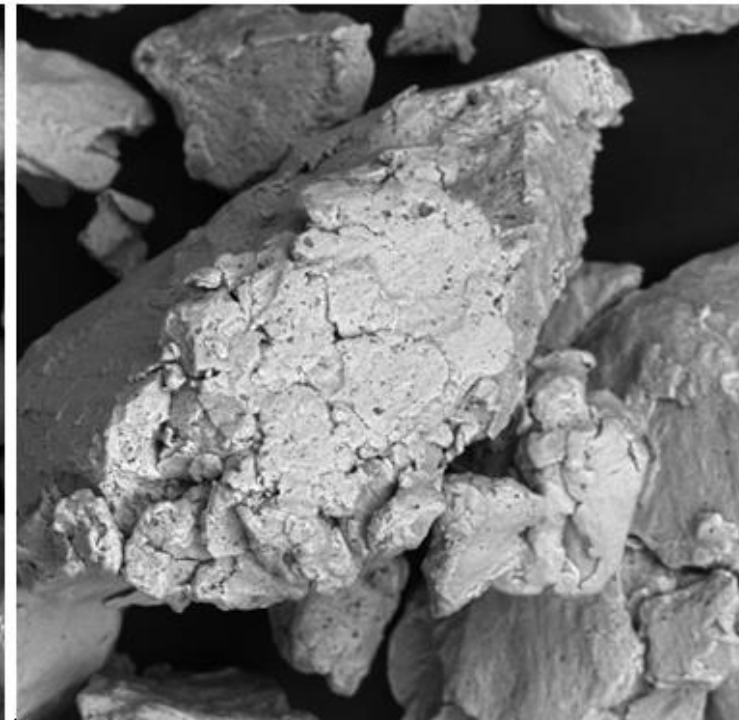

b)

\section{$100 \mu \mathrm{m}$}

Figure 3. SEM (BSE) micrographs of Fe28Al powder particles: (a) original and (b) 1-h milled.

The ball milling process leads to the increase of materials hardness (see Figure 4). For the comparison of the initial and the 1-h milled powder, a simple explanation by mechanical strengthening might be sufficient. However, there are also other aspects for the hardness changes including the grain size refinement and the phase transformation $(\mathrm{B} 2 \rightarrow \mathrm{A} 2)$.

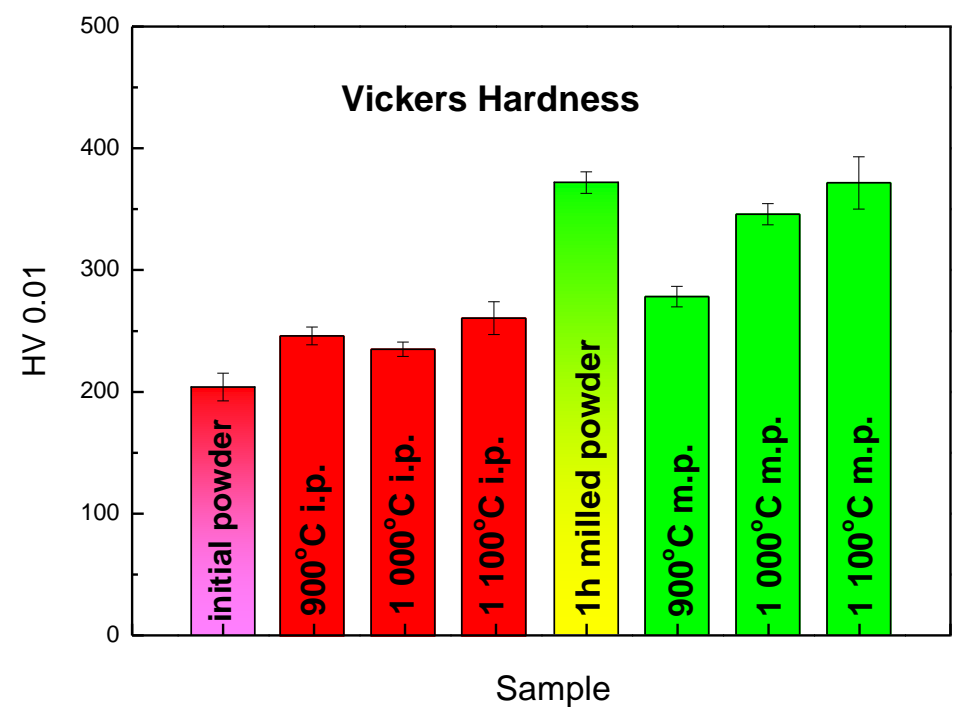

Figure 4. Hardness HV 0.01 of initials and 1-h milled Fe28Al powder and of SPS compacted Fe28Al from the initial powder sintered at $900{ }^{\circ} \mathrm{C}, 1000^{\circ} \mathrm{C}, 1100{ }^{\circ} \mathrm{C}$, and from 1 -h milled powder sintered at $900{ }^{\circ} \mathrm{C}, 1000^{\circ} \mathrm{C}$, and $1100{ }^{\circ} \mathrm{C}$.

The increase of hardness in case of the SPS compacted bulk materials from the initial powder is caused due to $\mathrm{B} 2 \rightarrow \mathrm{DO}_{3}$ phase transformation [36]. As shown in Figure 5, all the bulk materials are 
formed mainly by the $\mathrm{DO}_{3}$ phase $\left(\mathrm{Fe}_{3} \mathrm{Al}\right)$. The effect of phase transformation even compensated the expected decrease of hardness due to the grain coarsening during the compaction process.

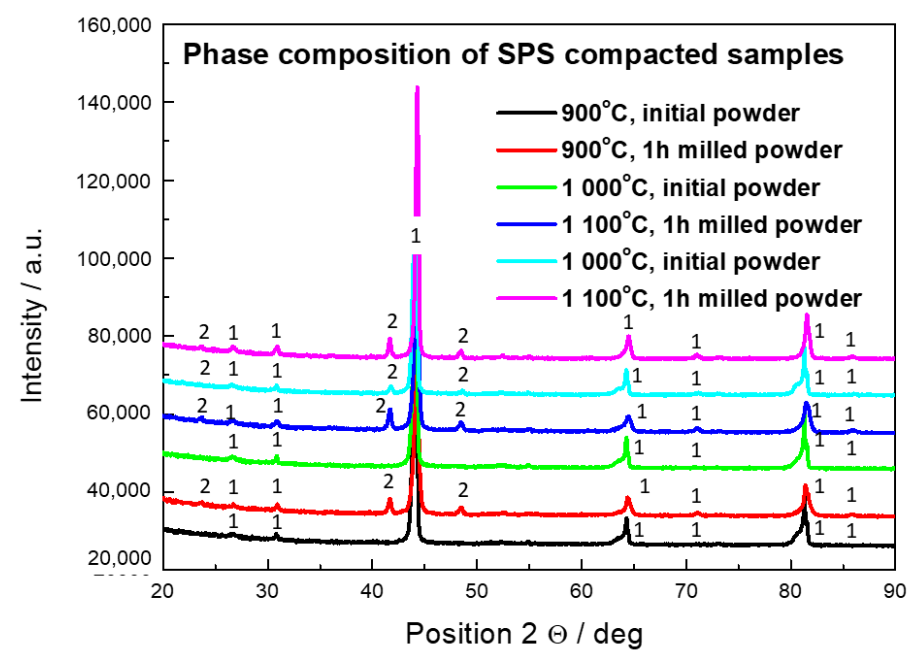

Figure 5. XRD diffraction pattern of SPS compacted Fe28Al from initial powder sintered at $900{ }^{\circ} \mathrm{C}$, $1000{ }^{\circ} \mathrm{C}$, and $1100{ }^{\circ} \mathrm{C}$ and from 1 -h milled powder sintered at $900{ }^{\circ} \mathrm{C}, 1000{ }^{\circ} \mathrm{C}$, and $1100{ }^{\circ} \mathrm{C}, 1-\mathrm{D}_{3}$ $\mathrm{FeAl}, 2-\mathrm{Fe}_{3} \mathrm{AlC}_{0.5}$.

The bulk material sintered from the initial powder at the highest temperature $\left(1100{ }^{\circ} \mathrm{C}\right)$ contained a small amount of a $\mathrm{Fe}_{3} \mathrm{AlC}_{0.5}$ carbide. The energy of $\mathrm{Fe}_{3} \mathrm{AlC}_{0.5}$ carbide formation equals $120 \mathrm{KJ} / \mathrm{mol}$ compared to $90 \mathrm{KJ} / \mathrm{mol}$ for $\mathrm{Fe}_{3} \mathrm{Al}$ [37]. This might be the reason why the carbides were not detected in the materials sintered at a lower temperature. The sources of the carbon are the die and the protection foil both form by graphite, used in the SPS process. The elevated temperature during the SPS process enables carbon diffusion. The effect of A2 $\leftrightarrow$ B2 phase transformation on diffusion of alloying elements in the matrix is negligible [38]. Based on this fact, it is possible to extrapolate the diffusion coefficients given in Reference [39] to the temperatures of SPS conditions. The carbon penetration depths calculated according to the parabolic law are $77 \mathrm{~nm}$ for $900{ }^{\circ} \mathrm{C}, 123 \mathrm{~nm}$ for $1000{ }^{\circ} \mathrm{C}$, and $190 \mathrm{~nm}$ for $1100{ }^{\circ} \mathrm{C}$. These amounts are under the detection of XRD, which implies that there is another method of carbon contamination than solid state diffusion. The carbon uptake during the sintering process is influenced by the used heating rate [40]. The parabolic law seems to be valid up to a heating rate of $10 \mathrm{~K} / \mathrm{s}$. The heating rate of $100 \mathrm{~K} / \mathrm{s}$ caused evaporation of carbon and its diffusion in a gas state in the pores [40]. The penetration depth in this case is significantly material dependent. It was reported that spinel sintered with a heating rate of $100 \mathrm{~K} / \mathrm{s}$ contained carbon contamination in the whole sample [41], while Sm sintered under the same conditions was contaminated to the depth of $10 \mu \mathrm{m}$ [42].

The amounts of the carbide in the bulk samples sintered from the 1-h milled powder are higher. The reason is contamination of the milled powder by carbon, which is not shown in Table 1 since carbon cannot be analyzed by XRF. On the other hand, the content of carbon in the stainless steel is less than $1 \%$. The more probable explanation is that the milled powder contains more pores and defects, which enables faster diffusion. The $\mathrm{Fe}_{3} \mathrm{AlC}_{0.5}$ peaks (at $41.8^{\circ}$ and $48.4^{\circ}$ ) are less pronounced for the material sintered at $900{ }^{\circ} \mathrm{C}$. This is in an agreement with the observation made for the materials sintered from the initial powder. At this temperature, the diffusion of carbon from the die and the foil is not significant and all the carbide content originates from the carbon that came to the material as a form of contamination during milling. The energy of carbide formation may again play its role. The hardness of the bulk material sintered from the milled powder at $900{ }^{\circ} \mathrm{C}$ is also very close to the values obtained from the materials sintered from the initial powder. The hardness values of materials sintered from the milled powder and the content of the $\mathrm{Fe}_{3} \mathrm{AlC}_{0}$ at 1000 and $1100{ }^{\circ} \mathrm{C}$ were higher. It was proven that the presence of the in-situ formed carbides leads to the higher hardness of the material [43]. 
Microstructures of the bulk materials are shown in Figure 6. Sintering at $900{ }^{\circ} \mathrm{C}$ leads to compact material with a high amount of residual porosity for both powder materials (see Table 3). The materials sintered at a temperature of $1000{ }^{\circ} \mathrm{C}$ also exhibited a high amount of residual porosity, but it is clear that the particles were sintered into larger islands of a compact material. Sintering at the highest temperature $-1100{ }^{\circ} \mathrm{C}$-leads to the formation of a bulk material with a negligible residual porosity in both cases. In the materials sintered from the milled powder, contamination by carbides is visible as black spots. In the material sintered from the initial powder at $1100{ }^{\circ} \mathrm{C}$, the boundaries of the individual powder particles are still visible, which might be caused by a thin oxide layer on the surface of the initial powder particles.

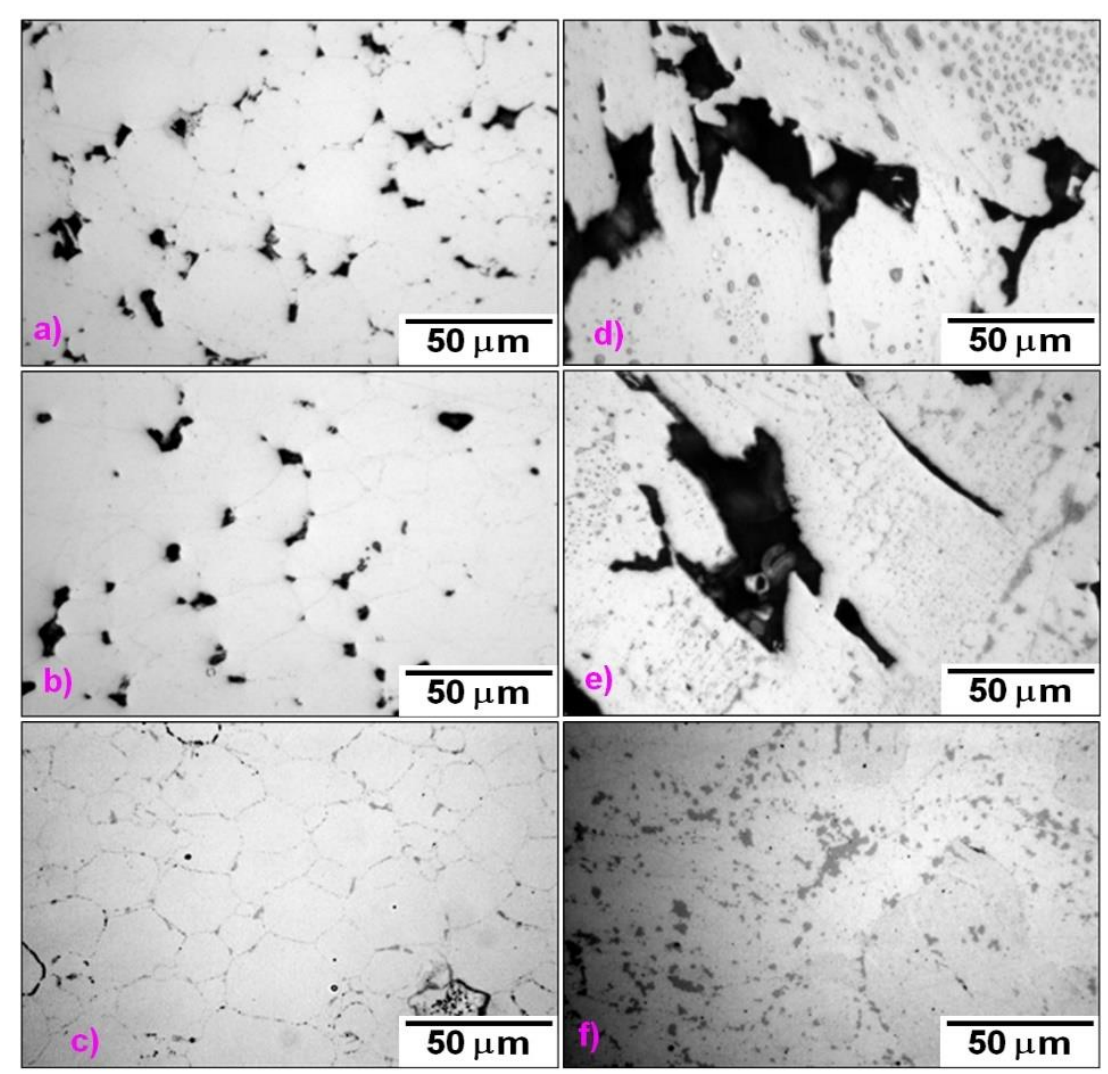

Figure 6. Optical micrographs of SPS compacted Fe28Al from the initial powder sintered at (a) $900{ }^{\circ} \mathrm{C}$, (c) $1000{ }^{\circ} \mathrm{C}$, and (e) $1100^{\circ} \mathrm{C}$ and from 1-h milled powder sintered at (b) $900{ }^{\circ} \mathrm{C}$, (d) $1000^{\circ} \mathrm{C}$, and (f) $1100{ }^{\circ} \mathrm{C}$.

The EBSD orientation maps were measured on the TEM samples, which explains the black holes in both materials in Figure 7 . The difference between the materials sintered at $1100{ }^{\circ} \mathrm{C}$ is remarkable. The material sintered from the initial powder is formed by polyhedral grains with a low grain-size distribution. On the other hand, the material sintered from the 1-h milled powder exhibited an extremely fine structure with bimodal distribution. Areas with nanometer-sized grains and areas with micrometer-sized grains. A similar structure was observed in $\mathrm{Fe}_{3} \mathrm{Al}$ material with 2 at\% [44]. 

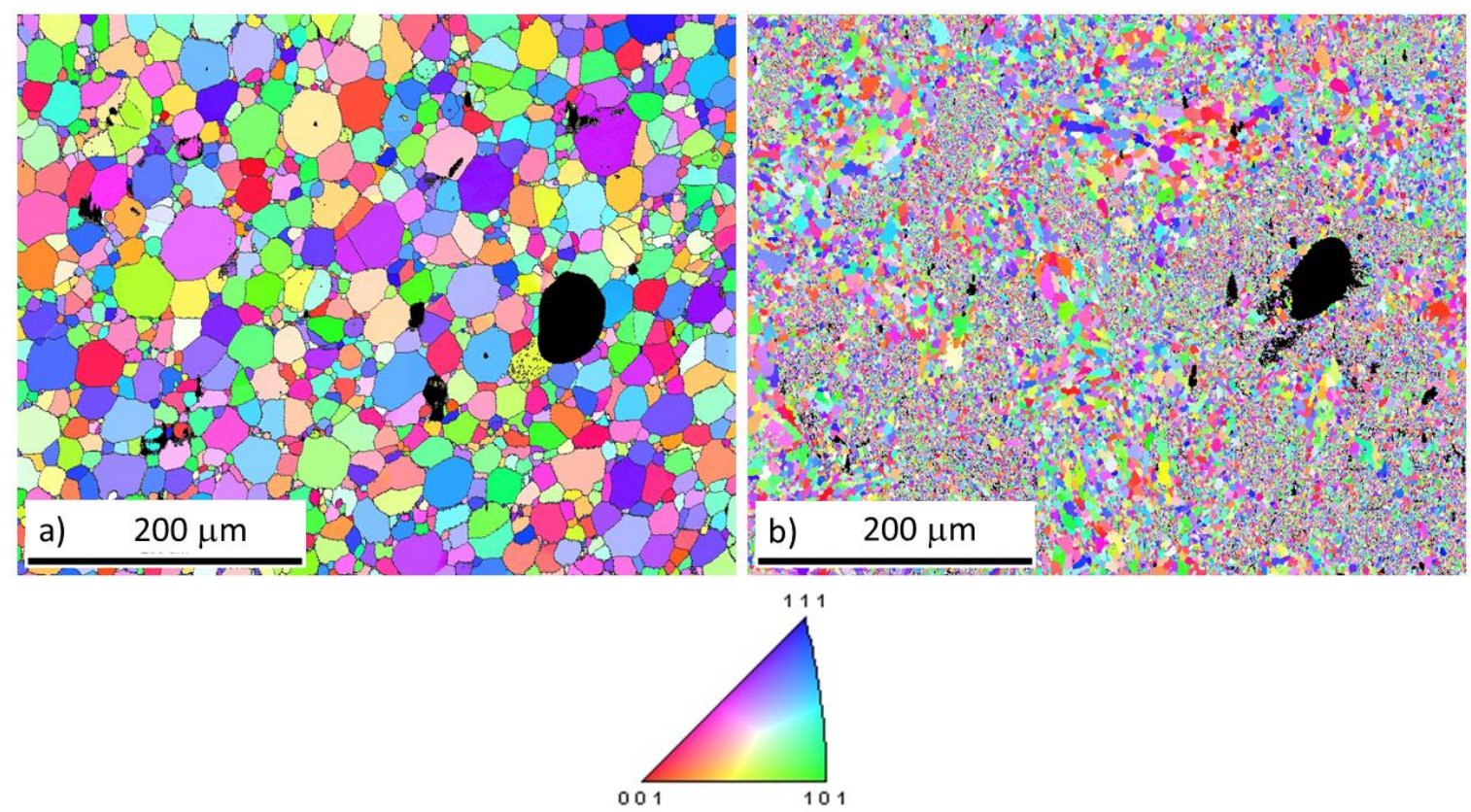

Figure 7. EBSD orientation maps of Fe28Al SPS compacted at $1100{ }^{\circ} \mathrm{C}$ sintered from (a) the initial and (b) the 1-h milled powder.

The results in Table 3 show porosity measured by image analysis and crystallite size determined by the Scherrer calculator. The grain size is obtained from EBSD data. The crystallite size is not very reliable since all the broadening of the XRD peaks was granted only to the grain size and the residual stresses were omitted.

Table 3. Porosity, crystallite size, and grain size of materials sintered at 900,1000 , and $1100{ }^{\circ} \mathrm{C}$ from Fe28Al powder in the initial state and after $1 \mathrm{~h}$ of milling. The crystallite size determined by Scherrer calculator. The grain size obtained from EBSD data.

\begin{tabular}{ccccc}
\hline $\begin{array}{c}\text { SPS Temperature } \\
{ }^{\circ} \mathbf{C}\end{array}$ & Powder & $\begin{array}{c}\text { Porosity } \\
\mathbf{\%}\end{array}$ & $\begin{array}{c}\text { Crystallite Size } \\
\mathbf{n m}\end{array}$ & $\begin{array}{c}\text { Grain Size } \\
\boldsymbol{\mu m}\end{array}$ \\
\hline 900 & Initial & $5.2 \pm 0.5$ & $410 \pm 56$ & - \\
1000 & Initial & $3.9 \pm 0.4$ & $501 \pm 83$ & - \\
1100 & Initial & $0.5 \pm 0.4$ & $562 \pm 89$ & $18.6 \pm 9.8$ \\
900 & 1 h milled & $18.7 \pm 1.3$ & $323 \pm 13$ & - \\
1000 & 1 h milled & $14.2 \pm 0.9$ & $286 \pm 62$ & - \\
1100 & 1 h milled & $0.4 \pm 0.2$ & $561 \pm 141$ & $5.9 \pm 3.0$ \\
\hline
\end{tabular}

A detailed microstructural observation carried out by TEM of the materials sintered at $1100{ }^{\circ} \mathrm{C}$ is given in Figure 8. Figure 8a shows the microstructure of the SPS compacted material sintered from the initial powder. Dark spots are oxide particles along the boundaries of the initial powder particles. The oxide particles do not form a homogeneous layer, which enables successful compaction of the material. Grains are visible inside of the sintered particles distinguishable by a different type of boundary. At the grains' boundaries, the oxide particles are not present. From the limited field of view of TEM, the grains shown in Figure 8 a seem to be about $2-3 \mu \mathrm{m}$ in size. 


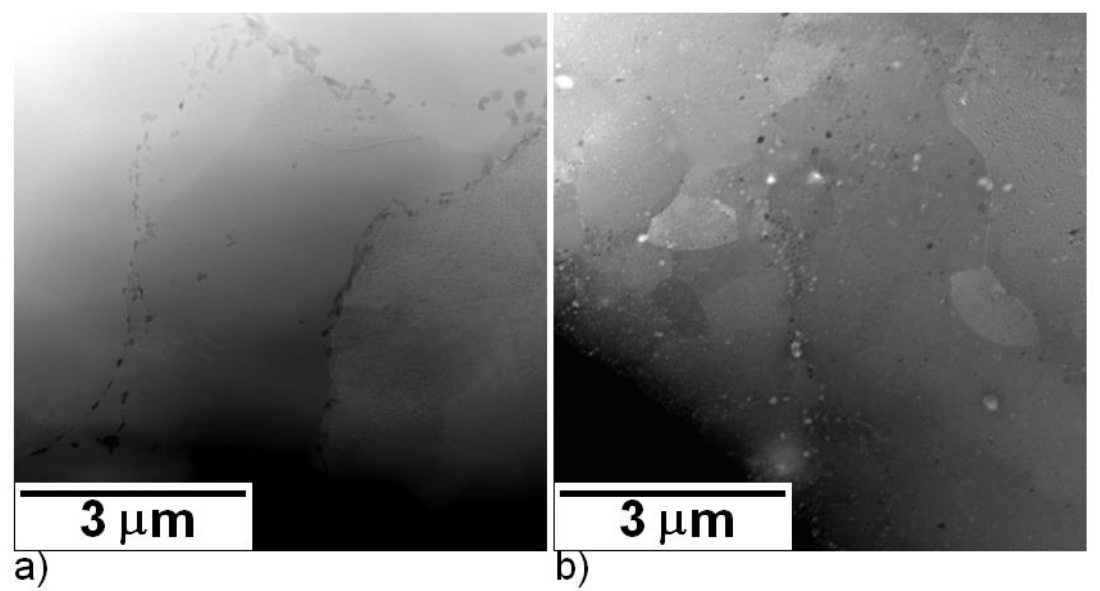

Figure 8. STEM/HAADF micrographs of Fe28Al spark plasma sintering (SPS) compacted at $1100{ }^{\circ} \mathrm{C}$ sintered from (a) initial powder and (b) 1-h milled powder.

Figure $8 \mathrm{~b}$ documents the microstructure of the material sintered from the 1-h milled powder at $1100^{\circ} \mathrm{C}$. It can be seen that the material contains a significant number of heterogeneous particles both heavier and lighter than Fe28Al matrix (oxides, carbides). The grain size of the material sintered from the 1-h milled powder is finer, at about $2-\mu \mathrm{m}$ in size (from the TEM micrographs).

Figure 9 shows the microstructure and the EDS elemental maps taken on the boundary of the initial powder particles in the materials sintered at $1100{ }^{\circ} \mathrm{C}$ from the initial powder. It can be seen that the boundary is decorated by fine oxide particles.
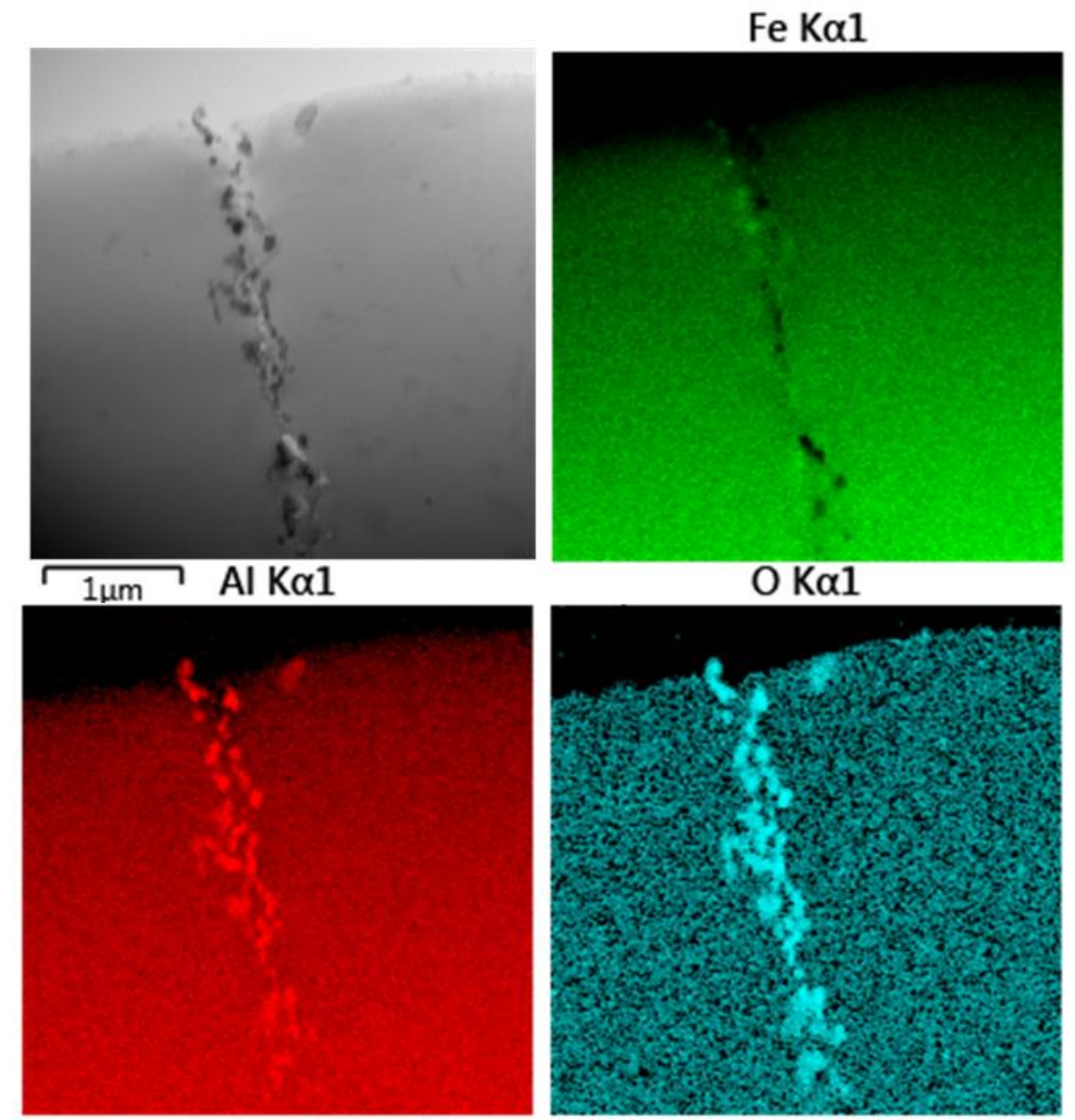

Figure 9. STEM/BF detailed micrographs and EDS elemental maps of Fe28Al SPS compacted at $1100{ }^{\circ} \mathrm{C}$ sintered from the initial powder. 
Figure 10 shows the microstructure and the EDS elemental maps in the materials sintered at $1100{ }^{\circ} \mathrm{C}$ from the 1 -h milled powder. One carbide particle can be seen in the micrograph and $\mathrm{Fe}, \mathrm{Al}$, and $\mathrm{C}$ elemental maps. The $\mathrm{Cr}$ distribution is uniform, which is caused be good diffusion of $\mathrm{Cr}$ in the $\mathrm{Fe}_{3} \mathrm{Al}$ matrix [45] even when the $\mathrm{Cr}$ originates from the stainless steel [46].
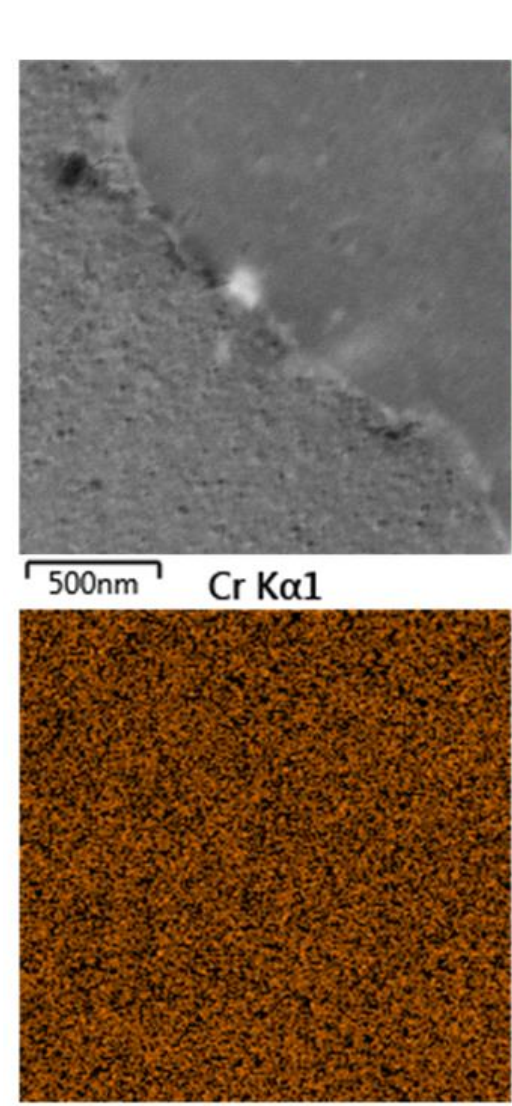

Fe K $\alpha 1$

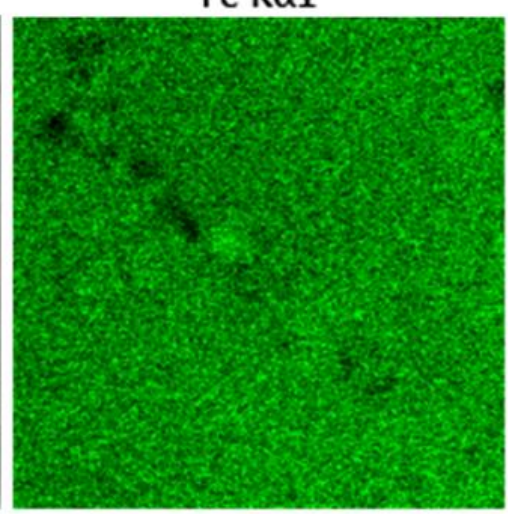

$\mathrm{O} K \alpha 1$

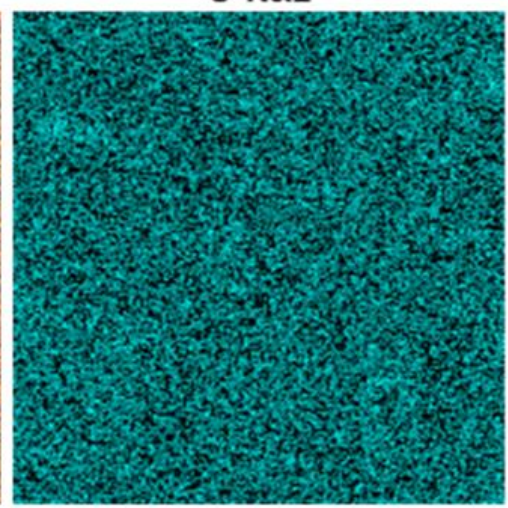

Al K $\alpha 1$

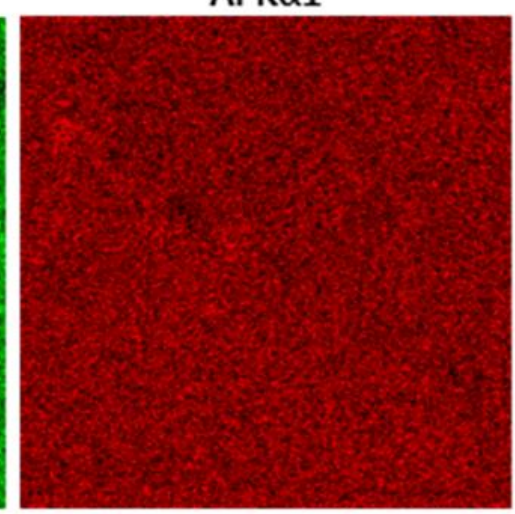

C Ka1_2

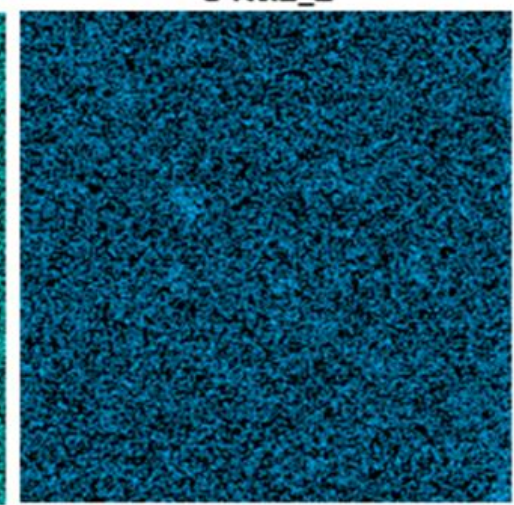

Figure 10. STEM/BF detailed micrographs and EDS elemental maps of Fe28Al SPS compacted at $1100{ }^{\circ} \mathrm{C}$ sintered from $1-\mathrm{h}$ milled powder.

Based on the results shown above, two main hypotheses about the difference in the hardness of the sintered materials can be discussed. The material sintered from the milled powder is strengthened by both dispersoids and the different phase transformation when compared with the material sintered from the initial powder. Due to its large interaction volume, a high-resolution neutron diffraction was performed in order to determine some differences in the structure of the matrix. The patterns obtained by the neutron diffraction contain information from the whole analyzed sample and not only from the surface layer, as it would be for the XRD.

Figures 11-13 shows the analyzer rocking curves for the FeAl samples. Figure 11 shows the effect of the ball milling on FWHM (full weight in half maximum) of the analyzer rocking curves for the initial powder sample and the 1-h milled one. It can be seen from Figure 11 that the effect is remarkable. The conversion of the $\Delta \theta_{\mathrm{A}}$ angles to $\Delta \mathrm{d}_{\mathrm{S}} / \mathrm{d}_{\mathrm{S}}$ provides the values of $\mathrm{FWHM}\left(\Delta \mathrm{d}_{\mathrm{S}} / \mathrm{d}_{\mathrm{S}}\right)$ of $3.18 \times 10^{-3}$ and $9.80 \times 10^{-3}$ for the Fe28Al initial and the Fe28Al milled samples, respectively. 


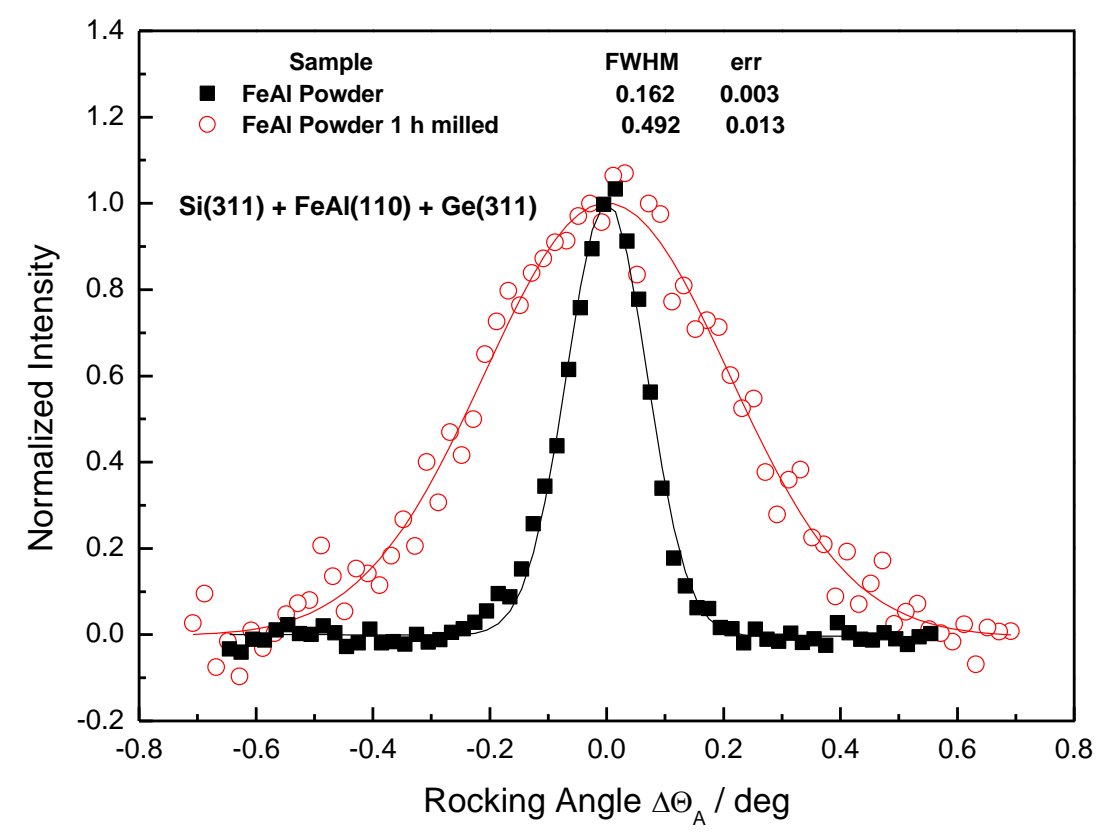

Figure 11. Analyzer rocking curves for the Fe28Al initial powder and the Fe28Al 1-h milled powder.

Subsequently, the SPS compacted samples were investigated and the related results are shown in Figures 12 and 13. Although the peak shapes of both powders were significantly different, the shapes of all sintered materials-independently of the pre-processing of the powder and sintering temperature-were similar. Since the samples were of different geometries, the curves were normalized to the zero position on the x-label. Because of this reason, the individual shifts of the peak position brought about by a possible change of the mean value of the lattice constant $\Delta \mathrm{d}_{\mathrm{S}}$ could not be evaluated.

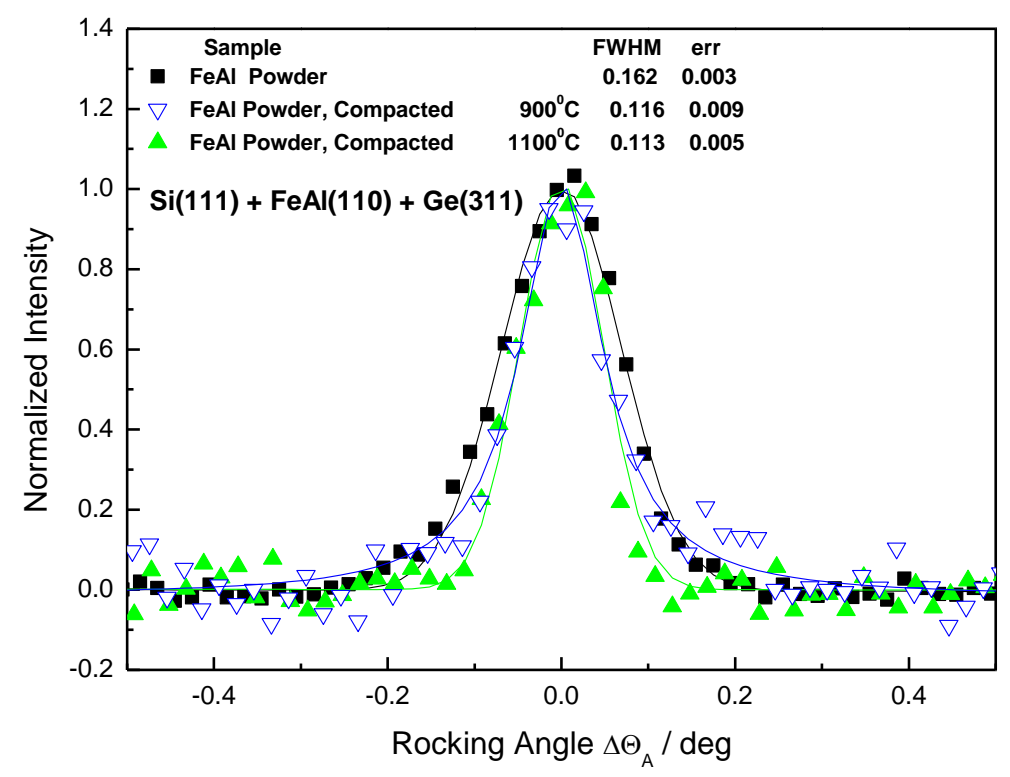

Figure 12. Analyzer rocking curves for the SPS compacted Fe28Al from the initial powder sintered at $900{ }^{\circ} \mathrm{C}, 1000^{\circ} \mathrm{C}$, and $1100{ }^{\circ} \mathrm{C}$.

Figure 13 shows a comparison of the 1-h milled powder and the bulk material sintered from it. The FWHM of the rocking curve from the bulk material sintered at $900{ }^{\circ} \mathrm{C}$ is within the experimental error, which is similar to the curves obtained from the materials sintered from the initial powder. 


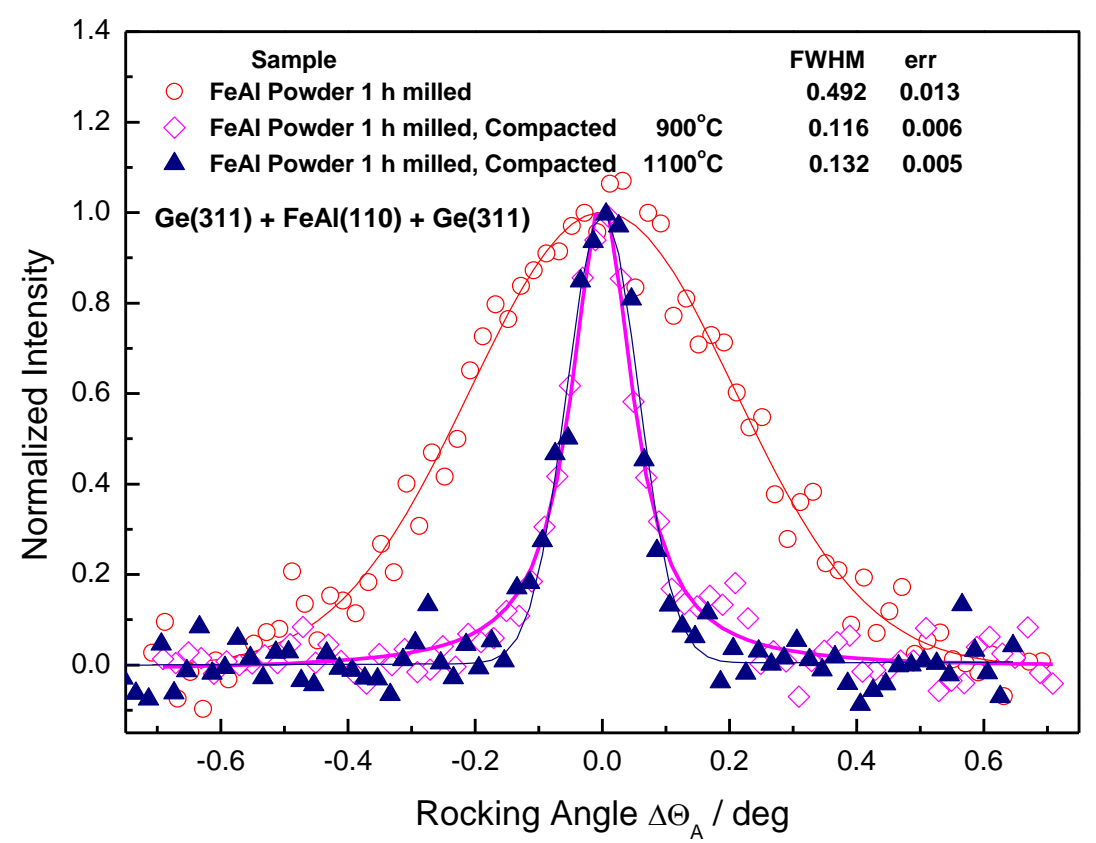

Figure 13. Analyzer rocking curves for the SPS compacted Fe28Al from 1-h milled powder sintered at $900{ }^{\circ} \mathrm{C}, 1000^{\circ} \mathrm{C}$, and $1100{ }^{\circ} \mathrm{C}$.

The rocking curve from the bulk material sintered at $1100{ }^{\circ} \mathrm{C}$ is slightly broader than the others obtained from bulk materials. This is most likely a mixed effect of the phase transformation and recrystallization kinetics and precipitation of oxides and carbides. Due to the accumulated stress in the 1-h milled powder, it is not possible to direct the diffraction line broadening to the rise of precipitates directly. The other factor is that SPS heating is fast and it is equivocal with the structure of the Fe28Al present during sintering.

To summarize neutron diffraction results, the milling brings about plastic deformation of the FeAl particles with a large distribution of the lattice spacing $d_{S}$, which results in a large FWHM of the rocking curve. On the other hand, the sintering at the high temperature works as annealing, which makes the rocking curves much narrower with FWHM close to the one corresponding to the experimental resolution of the diffractometer setting with the standard $\alpha-\mathrm{Fe}(110)$ sample (approximately $0.1 \mathrm{deg}$ ).

After the description of the microstructure, it was necessary to evaluate the success of the sintering process. Figure 14 shows the fracture surfaces after an impact test of the SPS compacted Fe28Al from the initial powder sintered at $900{ }^{\circ} \mathrm{C}, 1000{ }^{\circ} \mathrm{C}$, and $1100{ }^{\circ} \mathrm{C}$. The material sintered at $900{ }^{\circ} \mathrm{C}$ breaks completely along the surfaces of the initial particles. With an increasing sintering temperature, the fraction of inter-particular fracture is increasing even for material not fully inter-particular, but sintered at $1100^{\circ} \mathrm{C}$. This surface exhibits a brittle fracture with a river pattern.

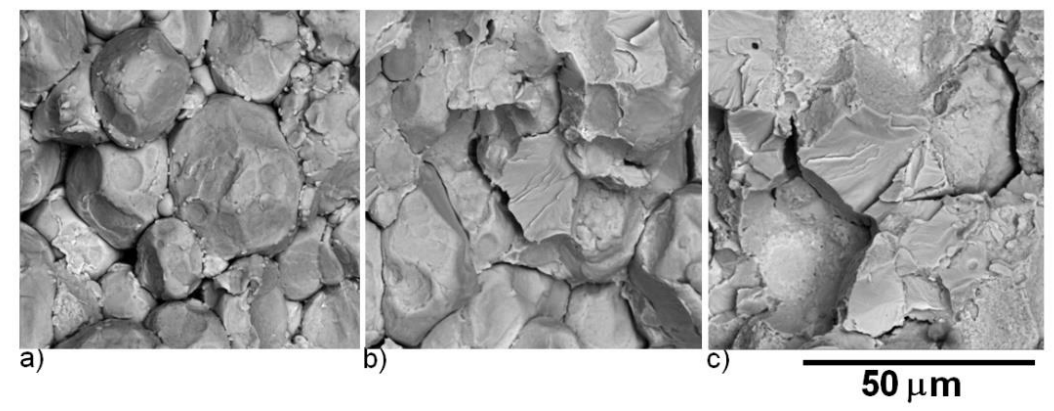

Figure 14. SEM (BSE) micrographs of fracture surfaces of SPS compacted Fe28Al from the initial powder sintered at (a) $900{ }^{\circ} \mathrm{C}$, (b) $1000{ }^{\circ} \mathrm{C}$, and (c) $1100{ }^{\circ} \mathrm{C}$. 
As shown in Figure 15, the fracture surface of the material sintered at $900{ }^{\circ} \mathrm{C}$ from the 1 -h milled powder is similar to the material sintered at the same temperature from the initial powder. The material sintered at $1000{ }^{\circ} \mathrm{C}$ exhibited a mixed fracture. The inter-particular fracture surface had a cup and cone pattern typical for a ductile fracture. This type of facture surface was observed within the whole sample sintered at $1100{ }^{\circ} \mathrm{C}$ from the 1 -h milled powder.

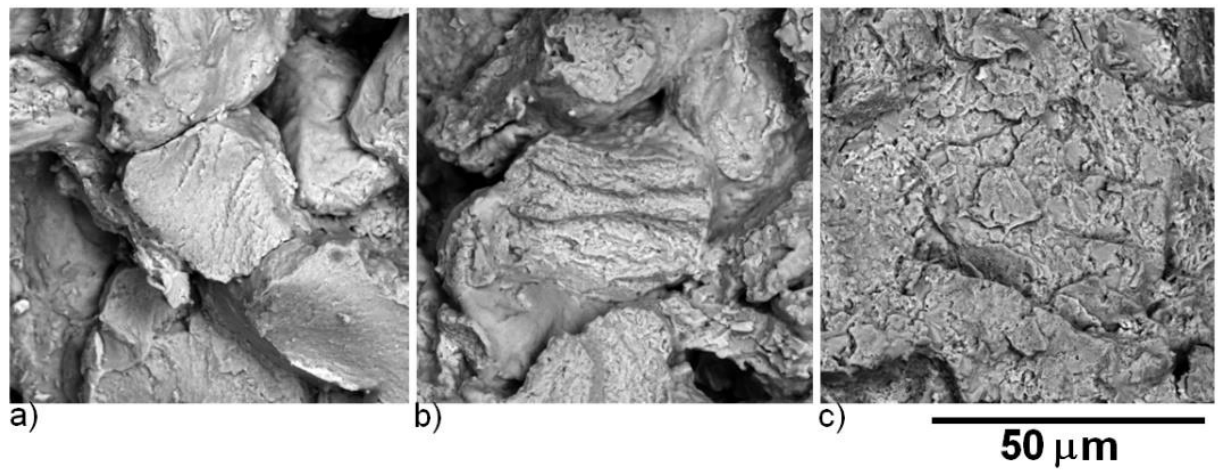

Figure 15. SEM (BSE) micrographs of fracture surfaces of the SPS compacted Fe28Al from the 1-h milled powder sintered at (a) $900^{\circ} \mathrm{C},(\mathbf{b}) 1000^{\circ} \mathrm{C}$, and (c) $1100{ }^{\circ} \mathrm{C}$.

It has already been found that the addition of 2-6 at.\% of $\mathrm{Cr}$ leads to improving the ductility of the Fe28Al alloy [13]. The 1-h milled alloy contained $0.9 \mathrm{wt} . \%$ of $\mathrm{Cr}$, which corresponds to 0.9 at. $\%$ in the actual composition. It is highly probable that the change in the fracture mechanism is connected with the Cr contamination.

\section{Materials and Methods}

In this work, the powder Fe-28 al.\% Al (16 wt.\%) prepared by nitrogen gas atomization was used. The powder was $0.5,1$, and $8 \mathrm{~h}$ milled using a planetary ball mill Retsch PM 100 (Retsch GmbH, Haan, Germany). For each batch, $5 \mathrm{~g}$ of the powder was taken and the ball-to-powder weight ratio of 10:1 at $400 \mathrm{rpm}$. The Ar protective atmosphere was used. The milling vessel and the milling balls (with a diameter of $1.1 \mathrm{~cm}, 10$ balls were used) were made from stainless steel (18/10).

The initial and the 1-h milled powders were compacted using the FCT HP D 10 SPS machine (FCT Systeme HP D 10, Rauenstein, Germany). The SPS process was performed for 5 min under the Ar protective atmosphere at temperatures of 900,1000 , and $1100{ }^{\circ} \mathrm{C}$. The graphite die was used with the separating graphite foils. The heating regime in the SPS was used. Ramping at the intended temperature with a heating rate of $200 \mathrm{~K} / \mathrm{min}$ was followed by simultaneously applying a uniaxial force of $15 \mathrm{kN}$ (48 $\mathrm{mPa}$ ) and heat. The amount of $10 \mathrm{~g}$ was used for every compaction, which resulted in a cylindrical sample with a 19-mm diameter and a height between 4.5 and $5.5 \mathrm{~mm}$.

The hardness of the samples was measured using the Future-Tech FM-700 device (Future-Tech Corp, Tokyo, Japan). The hardness was measured on embedded metallographic samples. At least 10 indents were measured using a load of $10 \mathrm{~g}$ with a 10 -s dwell time.

The powders and the bulk samples were observed by Olympus PME3 optical microscope (Tokyo, Japan), by TESCAN VEGA 3LMU (20 kV accelerating voltage) (Brno, The Czech Republic) scanning electron microscope, TESCAN FERA 3 (EBSD mapping, $15 \mathrm{kV}$ accelerating voltage, step $0.8 \mu \mathrm{m}$ ) (Brno, The Czech Republic) and by Jeol 2200 FS transmission electron microscope (200 kV accelerating voltage) (Jeol, Akishima, Japan). The TEM samples were prepared by ion polishing using the Gatan PIPs (Precision Ion Polishing system) (Gatan, Pleasanton, CA, USA).equipment.

The chemical composition was measured by XRF analysis was performed by ARL 9400 XP (XRF, ARL 9400 XP, Thermo ARL, Switzerland). The phase composition was analyzed by XRD using PANanalytical X'Pert PRO spectrometer (Panalytical, Almelo, The Netherlands).

Porosity was evaluated from optical micrographs using Image J 1.37v software (Wisconsin, WI, USA). 
To obtain an additional microstructural information, the unconventional high-resolution neutron diffraction setting was exploited [47,48]. Figure 16 shows the schematic drawing of the three axis neutron optics diffractometer (installed at the Řež medium power research reactor LVR-15) (̌̌ež, Czech Republic), which was used for the experiment. By rocking the optimally curved analyzer, this setting is suitable for detail studies of individual diffraction lines. The studied Fe28Al samples were in the form of small plates of the dimensions of about $10 \times 4 \times 2 \mathrm{~mm}^{3}$ (length $\times$ width $\times$ thickness) and inserted in the neutron beam in the vertical position. Since the samples were not precisely of the same dimensions, the irradiated volumes were slightly different and, therefore, we could not compare the detector signal related to individual samples.

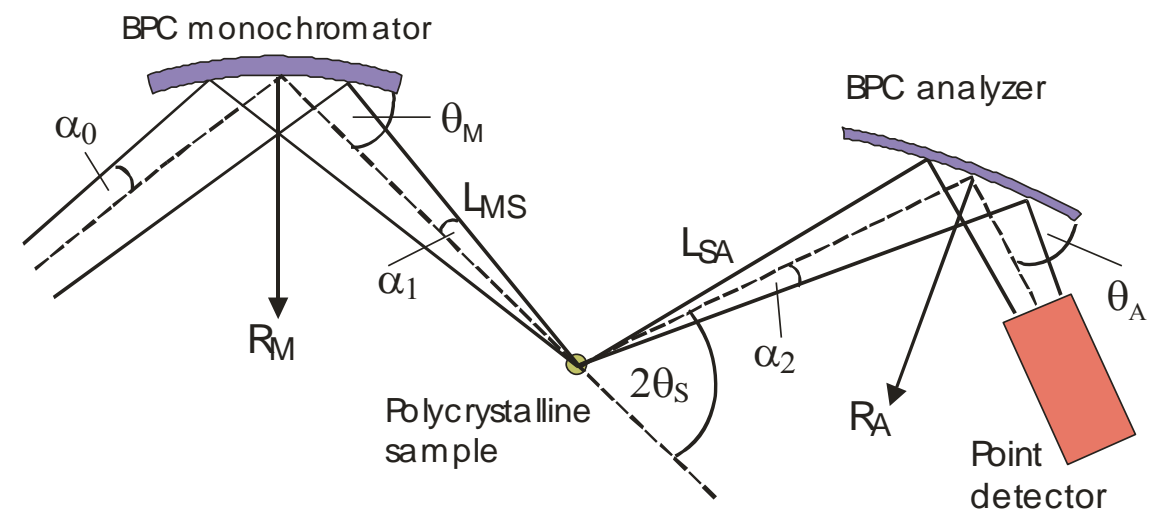

Figure 16. Schematic drawing of the three-axis diffractometer setting employing a BPC monochromator and analyzer (as used in the experiment, $R_{M}, R_{A}$-radii of curvature, $\theta_{M}, \theta_{A}-$ Bragg angles) and operating at the neutron wavelength of $\lambda=0.162 \mathrm{~nm}$.

\section{Conclusions}

The initial Fe28Al powder was milled for $0.5,1$, and $8 \mathrm{~h}$. It was proven that the milling leads to $\mathrm{B} 2 \rightarrow$ A2 phase transformation and to a contamination dependence on the milling time. The initial powder and the 1 -h milled powder were compacted by SPS at 900,1000 , and $1100{ }^{\circ} \mathrm{C}$. The materials sintered at $900{ }^{\circ} \mathrm{C}$ exhibited fully brittle fracture behavior in both cases. The fracture surface of the material sintered from the initial powder at $1100{ }^{\circ} \mathrm{C}$ was mixed between brittle and ductile. On the other hand, the behavior of the material sintered from the $1 \mathrm{~h}$ milled powder at $1100{ }^{\circ} \mathrm{C}$ was ductile. The difference between these materials was tested by the microscopy as well as the XRD and the neutron diffraction methods. It was proven that, although the structure of the initial powder (B2) and the milled powder (A2) were different, both provided the material with the same structure $\left(\mathrm{D0}_{3}\right)$, which had similar structural parameters. The difference in properties (higher hardness) and behavior (ductility) was caused by the change in chemical composition during the milling process.

Author Contributions: Conceptualization, D.V. Writing-original draft preparation and TEM microscopy, A.M. Sample preparation, M.Ö. Neutron diffraction, P.M. SEM microscopy, A.K. SPS processing, I.M. EBSD mapping, J.K. All authors have read and agreed to the published version of the manuscript.

Funding: This work was supported from the grant of Specific university research-grant No. A1_FCHT_2020_Neutron diffraction measurements were carried out at the CANAM infrastructure of the NPI CAS Řež supported through MŠMT project LM. The presented results were also supported in the frame of LM2015074 infrastructural MŠMT project “Experimental nuclear reactors LVR-15 and LR-0". The authors acknowledge the assistance in TEM sample preparation provided by the Research Infrastructure NanoEnviCz, supported by the Ministry of Education, Youth, and Sports of the Czech Republic, under Project No. LMJ.K acknowledge the support by Solid21 CZ.02.1.01/0.0/0.0/16_019/0000760.

Acknowledgments: We thank B. Michalcová from NPI ASCR for her significant help in the measurements and basic elaboration of the data.

Conflicts of Interest: The authors declare no conflict of interest. 


\section{References}

1. Suryanarayana, C. Mechanical alloying and milling. Prog. Mater. Sci. 2001, 46, 1-184. [CrossRef]

2. Zhu, S.M.; Tamura, M.; Sakamoto, K.; Iwasaki, K. Characterization of Fe3Al-based intermetallic alloys fabricated by mechanical alloying and HIP consolidation. Mater. Sci. Eng. A 2000, 292, 83-89. [CrossRef]

3. Park, B.G.; Ko, S.H.; Park, Y.H.; Lee, J.H. Mechanical properties of in situ Fe3Al matrix composites fabricated by MA-PDS process. Intermetallics 2006, 14, 660-665. [CrossRef]

4. Krasnowski, M.; Grabias, A.; Kulik, T. Phase transformations during mechanical alloying of $\mathrm{Fe}-50 \% \mathrm{Al}$ and subsequent heating of the milling product. J. Alloys Compd. 2006, 424, 119-127. [CrossRef]

5. Pang, L.; Kumar, K.S. Mechanical behavior of an Fe-40Al-0.6C alloy. Acta Mater. 1998, 46, 4017-4028. [CrossRef]

6. Moris, D.G.; Munos-Moris, M.A.; Chao, J. Development of high strength, high ductility and high creep resistant iron aluminide. Intermetallics 2004, 12, 821-826. [CrossRef]

7. Varin, R.A.; Bystrzycki, J.; Calka, A. Effect of annealing on the microstructure, ordering and microhardness of ball milled cubic (L12) titanium trialuminide intermetallic powder. Intermetallics 1999, 7, 785-796. [CrossRef]

8. Deevi, S.C.; Gedevanishvili, S.; Paldey, S. Iron Aluminide Fuel Injector Component. U.S. Patent No. 6489043, 3 December 2002.

9. Morris, D.G.; Munoz-Morris, M.A. Recent Developments Toward the Application of Iron Aluminides in Fossil Fuel Technologies. Adv. Eng. Mater. 2010, 13, 43-47. [CrossRef]

10. Palm, M.; Stein, F.; Dehm, G. Iron Aluminides. Annu. Rev. Mater. Res. 2019, 49, 297-326. [CrossRef]

11. LaBarge, W.J.; Anderson, C.; Kupe, J. Exhaust Manifold Comprising Aluminide. U.S. Patent No. 8020378, 20 September 2011.

12. Morris, D.G.; Morris-Munoz, M.A. The influence of microstructure on the ductility of iron aluminides. Intermetallics 1999, 7, 1121-1129. [CrossRef]

13. Grosdidier, T.; Ji, G.; Launois, S. Processing dense hetero-nanostructured metallic materials by spark plasma sintering. Scr. Mater. 2007, 57, 525-528. [CrossRef]

14. Paris, S.; Valot, C.; Gosmain, L.; Gaffet, E.; Bernard, F.; Munir, Z.; Valot, C. Investigation of mechanically activated field-activated pressure-assisted synthesis processing parameters for producing dense nanostructured FeAl. J. Mater. Res. 2003, 18, 2331-2338. [CrossRef]

15. Grosdidier, T.; Ji, G.; Bernard, F.; Gaffet, E.; Munir, Z.A.; Launois, S. Synthesis of bulk FeAl nanostructured materials by HVOF spray forming and Spark Plasma Sintering. Intermetallics 2006, 14, 1208-1213. [CrossRef]

16. Yang, G.J.; Wang, H.-T.; Li, C.J.; Li, C.-X. Effect of annealing on the microstructure and erosion performance of cold-sprayed FeAl intermetallic coatings. Surf. Coat. Technol. 2011, 205, 5502-5509. [CrossRef]

17. Łyszkowski, R.; Bystrzycki, J. Hot deformation and processing maps of a Fe-Al intermetallic alloy. Mater. Charact. 2014, 96, 196-205. [CrossRef]

18. Skoglund, H.; Wedel, M.K.; Karlsson, B. Processing of fine-grained mechanically alloyed FeAl. Intermetallics 2004, 12, 977-983. [CrossRef]

19. Senderowski, C.; Bojar, Z.; Wołczyński, W.; Pawłowski, A. Microstructure characterization of D-gun sprayed $\mathrm{Fe}-\mathrm{Al}$ intermetallic coatings. Intermetallics 2010, 18, 1405-1409. [CrossRef]

20. Song, B.; Dong, S.; Coddet, P.; Liao, H.; Coddet, C. Fabrication and microstructure characterization of selective laser-melted FeAl intermetallic parts. Surf. Coatings Technol. 2012, 206, 4704-4709. [CrossRef]

21. Bernard, F.; Charlot, F.; Gaffet, E.; Munir, Z.A.J. One-Step Synthesis and Consolidation of Nanophase Iron Aluminide. J. Am. Ceram. Soc. 2001, 84, 910-914. [CrossRef]

22. Paris, S.; Gaffet, E.; Bernard, F.; Munir, Z. Spark plasma synthesis from mechanically activated powders: A versatile route for producing dense nanostructured iron aluminides. Scr. Mater. 2004, 50, 691-696. [CrossRef]

23. Elkedim, O.; Paris, S.; Phigini, C.; Bernard, F.; Gaffet, E.; Munir, Z. Electrochemical behavior of nanocrystalline iron aluminide obtained by mechanically activated field activated pressure assisted synthesis. Mater. Sci. Eng. A 2004, 369, 49-55. [CrossRef]

24. Ji, G.; Goran, D.; Bernard, F.; Grosdidier, T.; Gaffet, E.; Munir, Z.A. Structure and composition heterogeneity of a FeAl alloy prepared by one-step synthesis and consolidation processing and their influence on grain size characterization. J. Alloys Compd. 2006, 420, 158-164. [CrossRef] 
25. Sasaki, T.T.; Mukai, T.; Hono, K. A high-strength bulk nanocrystalline Al-Fe alloy processed by mechanical alloying and spark plasma sintering. Scr. Mater. 2007, 57, 189-192. [CrossRef]

26. Ji, G.; Grosdidier, T.; Bozzolo, N.; Launois, S. The mechanisms of microstructure formation in a nanostructured oxide dispersion strengthened $\mathrm{FeAl}$ alloy obtained by spark plasma sintering. Intermetallics 2007, 15, 108-118. [CrossRef]

27. Ko, I.-Y.; Jo, S.-H.; Doh, J.-M.; Yoon, J.-K.; Shon, I.-J. Rapid consolidation of nanostructured FeAl compound by high frequency induction heating and its mechanical properties. J. Alloys Compd. 2010, 496, L1-L3. [CrossRef]

28. Ji, G.; Bernard, F.; Launois, S.; Grosdidier, T. Processing conditions, microstructure and mechanical properties of hetero-nanostructured ODS FeAl alloys produced by spark plasma sintering. Mater. Sci. Eng. A 2013, 559, 566-573. [CrossRef]

29. Jian, W.; Xing, J.-D.; Tang, H.-P.; Yang, B.-J.; Li, Y.-N. Microstructure and mechanical properties of Fe3Al alloys prepared by MA-PAS and MA-HP. Trans. Nonferr. Met. Soc. China 2011, 21, 2408-2414. [CrossRef]

30. He, Q.; Jia, C.; Meng, J. Influence of iron powder particle size on the microstructure and properties of Fe3Al intermetallics prepared by mechanical alloying and spark plasma sintering. Mater. Sci. Eng. A 2006, 428, 314-318. [CrossRef]

31. Wang, J.; Xing, J.; Qiu, Z.; Zhi, X.; Cao, L. Effect of fabrication methods on microstructure and mechanical properties of Fe3Al-based alloys. J. Alloys Compd. 2009, 488, 117-122. [CrossRef]

32. Michalcová, A.; Senčekova, L.; Rolink, G.; Weisheit, A.; Pešička, J.; Stobik, M.; Palm, M. Laser additive manufacturing of iron aluminides strengthened by ordering, borides or coherent Heusler phase. Mater. Des. 2017, 116, 481-494. [CrossRef]

33. Skiba, T.; Haušild, P.; Karlík, M.; Vanmeensel, K.; Vleugels, J. Mechanical properties of spark plasma sintered FeAl intermetallics. Intermetallics 2010, 18, 1410-1414. [CrossRef]

34. Stein, F.; Palm, M. Re-determination of transition temperatures in the Fe-Al system by differential thermal analysis. Int. J. Mater. Res. 2007, 98, 580-588. [CrossRef]

35. Raabe, D.; Keichel, J. Microstructure and crystallographic texture of rolled polycrystalline Fe3AI. J. Mater. Sci. 1996, 31, 339-344. [CrossRef]

36. Ikeda, O.; Ohnuma, I.; Kainuma, R.; Ishida, K. Phase equilibria and stability of ordered BCC phases in the Fe-rich portion of the Fe-Al system. Intermetallics 2001, 9, 755-761. [CrossRef]

37. Noh, J.-Y.; Kim, H. Density Functional Theory Calculations on K-carbides, (Fe,Mn)3AlC. J. Korean Phys. Soc. 2011, 58, 285-290. [CrossRef]

38. Peteline, S.; Divinski, S.V.; Njiokep, E.M.T.; Mehrer, H. Diffusion of Solute Elements in Fe3Al. Defect Diffus. Forum 2003, 216, 175-180. [CrossRef]

39. Golovin, I.; Divinski, S.V.; Čížek, J.; Prochazka, I.; Stein, F. Study of atom diffusivity and related relaxation phenomena in Fe3Al-(Ti,Nb)-C alloys. Acta Mater. 2005, 53, 2581-2594. [CrossRef]

40. Morita, K.; Kim, B.; Yoshida, H.; Hiraga, K.; Sakka, Y. Assessment of carbon contamination in MgAl2O4 spinel during spark-plasma-sintering (SPS) processing. J. Ceram. Soc. Jpn. 2015, 123, 983-988. [CrossRef]

41. Morita, K.; Kim, B.; Yoshida, H.; Hiraga, K.; Sakka, Y. Distribution of carbon contamination in oxide ceramics occurring during spark-plasma-sintering (SPS) processing: II - Effect of SPS and loading temperatures. J. Eur. Ceram. Soc. 2018, 38, 2596-2604. [CrossRef]

42. Mackie, A.; Hatton, G.D.; Hamilton, H.G.; Dean, J.S.; Goodall, R. Carbon uptake and distribution in Spark Plasma Sintering (SPS) processed Sm(Co, Fe, Cu, Zr) z. Mater. Lett. 2016, 171, 14-17. [CrossRef]

43. Kant, R.; Prakash, U.; Agarwala, V.; Prasad, V.V.S. Microstructure and wear behaviour of FeAl-based composites containing in-situ carbides. Bull. Mater. Sci. 2016, 39, 1827-1834. [CrossRef]

44. Minamino, Y.; Koizumi, Y.; Tsuji, N.; Hirohata, N.; Mizuuchi, K.; Ohkanda, Y. Microstructures and mechanical properties of bulk nanocrystalline Fe-Al-C alloys made by mechanically alloying with subsequent spark plasma sintering. Sci. Technol. Adv. Mater. 2004, 5, 133-143. [CrossRef]

45. Pelleg, J. Diffusion in the Iron Group L12 and B2 Intermetallic Compounds; Springer International Publishing AG: Cham, Switzerland, 2017; p. 207.

46. Wang, J.; Li, Y.; Yin, Y. Interface characteristics in diffusion bonding of Fe3Al with Cr18-Ni8 stainless steel. J. Colloid Interface Sci. 2005, 285, 201-205. [CrossRef] [PubMed] 
47. Mikula, P.; Šaroun, J.; Stammers, J.; Em, V. High-resolution analysis with bent perfect crystal (BPC) in powder diffraction - I. J. Surf. Investig. X-ray, Synchrotron Neutron Tech. 2020, (in press).

48. Mikula, P.; Šaroun, J.; Stammers, J.; Em, V. High-resolution analysis with bent perfect crystal (BPC) in powder diffraction - II. J. Surf. Investig. X-ray Synchrotron Neutron Tech. 2020, (in press).

Sample Availability: Sample Availability: Not available.

(C) 2020 by the authors. Licensee MDPI, Basel, Switzerland. This article is an open access article distributed under the terms and conditions of the Creative Commons Attribution (CC BY) license (http://creativecommons.org/licenses/by/4.0/). 